thái đô̂ và hành vi trong quan hệ tình dục ở nam công nhân chưa kết hôn di cư tai khu công nghiệp Bình Xuyên-tỉnh Vinh Phúc. Luận vẳn thạc sỹ Y tế Công cộng, Trường Đại học Y tế Công cộng, Hà Nội. 2012.

6. Tổng cuc dân số - Kế hoach hóa gia đình. Nôi dung chủ yếu về chiến lược dân số và sức khỏe sinh sản Viêt Nam giai đoan 2011-2020. 2011.

7. Website with no named author; no publication or accessed dates. Total number of international migrants at mid-year 2019. Migration Data Portal. https://migrationdataportal.org/?i=stock_abs_\&t= 2019. Updated date September 18, 2019. Accessed date December 7, 2020.

8. WHO. Report on global sexually transmitted infection surveillance 2018. Geneva: World Health Organization; 2018. Licence: CC BY-NC-SA 3.0 IGO] https://www.who.int/reproductivehealth/publ ications/stis-surveillance-2018/en/. Accessed date December 7, 2020.

\title{
KẾT QUẢ SớM VÀ TRUNG HAN PHẪU THUÂT SỬA VAN HAI LÁ ÍT XÂM LẤN QUA ĐƯỜNG MỞ NHỎ NGỰC PHẢI TẠI BÊ̂NH VIỆN TIM HÀ NộI
}

\section{Trần Lê Công Thắng1, Nguyễn Sinh Hiền ${ }^{1,2}$, Nguyễn Minh Ngọc $^{2}$}

\section{TÓM TẮT}

Nghiên cứu hồi cứu mô tả 45 bênh nhân được phẫu thuât sửa van hai lá ít xâm lấn với nôi soi hỗ trợ tại Bệnh Viện Tim Hà Nội từ tháng 01/2018 đến tháng $12 / 2020$, với thời gian theo dõi sau mổ kéo dài trung bình 16,4 tháng. Tuổi trung bình là $49 \pm 12,5$ tuổi. Ti lệ nam/nữ xấp xỉ 1/1. Trong đó có 43 trường hợp van thoái hóa, 2 trường hợp van hậu thấp. Cơ chế chính là tổn thương lá sau (34 trường hợp), đứng thứ hai là tổn thương cả lá trước và lá sau có 7 trường hợp; tổn thương lá trước đơn thuần gồm 4 trường hợp. Thời gian chạy máy TNHCT $164 \pm 34$ phút, thời gian cặp đông mach chủ $93 \pm 19$ phút. Kỹ thuất tao hình van hai lá bao gồm: đặt vòng van $100 \%$, cắt tam giác/ tứ giác/ butterfly $48,9 \%$, khâu gấp nếp lá sau $24,4 \%$, dây chằng nhân tạo $20 \%$, edge-to-edge $13,3 \%$. Tỉ lệ tử vong trong bênh viện và 30 ngày sau mô là $0 \%$. 4 trường hợp có biến chứng trong đó bao gồm 2 trường hợp chảy máu phải mổ lại, 1 trường hợp tràn dịch màng phổi cần dẫn lưu $(2,2 \%), 1$ trường hợp nhiễm trùng vết mổ đùi sau mổ $(2,2 \%)$, không có trường hợp nào phải mổ lại thay van trong hoặc trong khi nẳm viện. Thời gian hồi sức trung bình $2,5 \pm 0,7$ ngày, thời gian thở máy $18.9 \pm 7,5$ giờ. Tất cả $45 \mathrm{ca}$ đều được phẫu thuật thành công, không có trường hợp nào phải mở rộng đường mở ngực hay chuyển mở xương ức. Tỉ lệ sửa van hai lá thành công cao (không hở hoăc hở đô I trên siêu âm sau mổ) $(95,6 \%)$

Tư khoá: phẫu thuật sửa van hai lá ít xâm lấn, đường mở nhỏ ngực phải.

\section{SUMMARY \\ EARLY AND MID-TERM OUTCOMES IN \\ MINIMALLY INVASIVE MITRAL VALVE REPAIR VIA RIGHT MINITHORACOTOMY AT HANOI HEART HOSPITAL}

\footnotetext{
${ }^{1}$ Trường Đại học Y Hà Nội

${ }^{2}$ Bênh viên Tim Hà Nôi

Chịu trách nhiệm chính: Trần Lê Công Thắng

Email: thang.otso@gmail.com

Ngày nhận bài: 2.8.2021

Ngày phản biên khoa hoc: 1.10 .2021

Ngày duyệt bài: 7.10.2021
}

This was a hospital-based cohort study including 45 retrospective patients who underwent minimally invasive mitral valve repair with endoscopic support at Hanoi Heart Hospital from January 2018 to December 2020, with prolonged postoperative follow-up. average 16.4 months. The mean age was $49 \pm 12.5$ years old. The male/female ratio is approximately $1: 1$. Patients with mitral valve repair included 43 degenerative valves, 2 post rheumatic valves. The main mechanism is damage to the posterior leaves (34 cases), the second is damage to both the anterior and posterior leaves in 7 cases; simple anterior leaf lesions include 4 cases. Cardiopulmonary bypass and aortic clamp times were $164 \pm 34$ and $93 \pm 19$ minutes. Mitral valve reshaping techniques include: annuloplasty $100 \%$, leaflet resection $48.9 \%$, folding $24.4 \%$, neochordae implantation $20 \%$, edge -to- edge $13.3 \%$. Overall, inhospital and 30-day mortality were $0 \%$. We encountered 4 complications including 2 cases of bleeding requiring reoperation, 1 case of 1 pleural effusion $(2.2 \%)$, 1 case of postoperative thigh infection (2.2\%). The ICU length of stay was $2.5 \pm 0.7$ days, and average time to extubation was $18.9 \pm 7.5$ hours. All 45 cases were successfully operated, there were no cases that had to widen the thoracotomy or sternotomy. The success rate of mitral valve repair is high. (95.6\%).

Keywords: Minimally invasive mitral valve repair, minithoracotomy.

\section{I. ĐĂTT VẤN ĐỀ}

Kể từ năm 1996, lần đầu tiên Carpentier đã thành công trong phẫu thuật van hai lá qua đường mở ngức nhỏ có nôi soi hỗ trơ cho đến nay, hơn 20 nằm qua, các bác sĩ phẫu thuật tim mạch trên thế giới đã và đang phát triển và hoàn thiện kĩ thuât trong lĩnh vực phẫu thuât ít xâm lấn. Kỹ thuẩt mổ này đã chứng minh được những ưu điểm như tính an toàn, tỷ lệ tử vong sau mổ thấp, giảm sang chấn, ít đau, ít chảy máu, giảm thời gian thở máy, hồi sức và nằm viên, tính thẩm mỹ cũng như giảm thiểu tỷ lê nhiếm trùng vết mổ và các biến chứng liên quan 
đến xương ức.

Bên cạnh đó, phẫu thuật van hai lá là một trong những phấu thuật được thực hiện nhiều ở các trung tâm mổ tim lớn, đặc biệt sửa van hai lá đóng một vai trò quan trọng. Đây là phương pháp đã được chứng minh mang lợi nhiều lợi ích cho bệnh nhân: Thời gian phục hồi nhanh, không cần phải sử dụng thuốc kháng đông loại kháng Vitamin $\mathrm{K}$ dài hạn, triệu chứng bệnh nhân cải thiện tốt hơn, suy tim phục hồi nhanh hơn và chất lượng cuộc sống bệnh nhân cao hơn.

Bởi vậy, kết hợp những ưu điểm của phẫu thuật van hai lá ít xâm lấn qua đường mở ngực nhỏ bên phải có nội soi hỗ trợ và ưu điểm của phẫu thuật sửa van hai lá sẽ mang lại một chất lượng điều trị cao cho bệnh nhân mắc bệnh van hai lá.

Trung tâm phẫu thuật tim mạch - Bệnh viện Tim Hà Nội là một trong số những đơn vị đầu tiên triển khai thành công sửa van hai lá ít xâm lấn qua đường mở ngực nhỏ bên phải có nội soi lồng ngực hỗ trợ. Chúng tôi thực hiện nghiên cứu này nhằm đánh giá kết quả bước đầu sau 03 năm thực hiện (từ tháng $1 / 2018$ đến tháng 12/2020) cũng như phân tích kinh nghiệm của chúng tôi về phương pháp này.

\section{II. ĐỐI TƯợNG VÀ PHƯƠNG PHÁP NGHIÊN CỨU \\ 2.1. Đối tượng nghiên cứu}

2.1.1. Tiêu chuẩn lựa chọn bệnh nhân. Bệnh nhân được chẩn đoán bệnh hỡ van hai lá, có chỉ định sửa van hai lá, được phẫu thuật sửa van hai lá ít xâm lấn qua đường mở ngực nhỏ bên phải tại Trung tâm phẫu thuật Tim mạch bệnh viện Tim Hà Nội từ tháng 01/2018 đến tháng 12/2020.

Bệnh nhân đồng ý tham gia nghiên cứu.

Bệnh nhân có thông tin hồ sơ đầy đủ.

\subsubsection{Tiêu chuẩn loại trừ}

- Bệnh nhân được phẩu thuật sửa van hai lá bằng đường mổ mở truyền thống qua đường mở cưa xương ức.

- Bệnh nhân có biến dạng lồng ngực

- Bệnh nhân có các bểnh lý tim phối hợp cần sửa chữa bằng phẫu thuật: bệnh động mạch chủ, bệnh van hai lá, van ba lá.

- Bệnh nhân có phẫu thuật lồng ngực trước đó, như gây dính màng phổi, cắt thùy phổi, cắt kén khí phổi.

- Bệnh nhân có viêm màng ngoài tim hoặc có xạ trị vùng ngực trước đó.

- Bệnh nhẩn không đồng ý tham gia nghiên cứu, hồ sơ bệnh án không đầy đủ, thiếu thông tin.

\subsection{Phương pháp nghiên cứu}

- Hồi cứu mô tả loạt ca (Số liệu lấy qua hồ sơ bệnh án, tái khám và gọi điện đánh giá tất cả bệnh nhân)

\subsection{Mô tả quy trình phẫu thuât:}

+ Gây mê và chuẩn bị bệnh nhân: Bệnh nhân được gây mê nội khí quản, dùng ống nội khí quản một nòng hoặc hai nòng đối với người lớn. Theo dỗi huyết áp và điện tim. Đặt sonde tiểu, sonde dạ dày, đặt catheter $\mathrm{DM}$, catheter TM trung ương, bản điện cực chống rung ngoài, đâu dò siêu âm thực quản. Đặt tư thế bệnh nhân nằm nghiêng trái $30^{\circ}$ hai tay để xuôi dọc theo cơ thể. Sát trùng trường mổ từ cằm xuổng 2 đùi. Trải toan vô khuẩn.

\section{+ Các bước kỹ thuật}

- Đặt trocart $5 \mathrm{~mm}$ khoang liên sườn IV đường nách giữa phải đưa optic nội soi. Mở ngực đường bên phải, rạch da 4-6cm phía trước hoặc phía trước bên, mở vào màng phổi vị trí khoang liên sườn IV. Rach da vùng bẹn phải, bộc lộ động mạch và tînh mạch đùi. Cho heparin toàn thân liêu $300 \mathrm{UI} / \mathrm{Kg}$, đặt cannula động mạch đùi luồn tới động mạch chậu ngoài. Cannula tĩnh mạch chủ dưới được đặt vào tĩnh mạch đùi luồn lên nhĩ phải dưới hỗ trợ siêu âm. Cannula tĩnh mạch chủ trên được đặt qua đường tĩnh mạch cảnh trong. Đặt camera: chọc Trocart qua khoang liên sườn II đường nách trước

- Mở màng tim phía trên dây hoành 1,5 $2 \mathrm{~cm}$, mở rộng lên phía tĩnh mạch chủ trên, khâu treo màng tim. Bộc lộ nhĩ trái, nhĩ phải, rãnh liên nhĩ. Chạy máy tim phổi nhân tạo với hai tĩnh mạch chủ. Đặt kim truyền dung dịch liệt tim vào gốc động mạch chủ. Bơm khí CO2 vào khoang màng tim, tư thế bệnh nhân đầu thấp. Dùng dụng cụ cặp ĐM chủ luồn qua khoang liên sườn 3 hoặc 4 đường nách trước - giữa. Cặp động mạch chủ. Bơm dung dịch liệt tim xuôi dòng qua kim gốc động mạch chủ. Có thể sử dụng dung dịch liệt tim cao phân tử hoặc dung dịch máu ấm. Trường hợp dùng dung dịch liệt tim máu ấm cần bơm lại mồi 15 phút.

- Sau khi tim ngừng đập mở nhĩ trái qua đường rãnh liên nhĩ (rãnh Waterson), bộc lộ van hai lá, đánh giá tổn thương van hai lá. Tiến hành sửa van hai lá: Thường là chuyển vị dây chằng hoặc tạo hình dây chằng nhân tạo, sửa theo phương pháp Carpentier, gọt bỏ mồ van, xẻ mép van... Chọn kích thước vòng van nhân tạo phù hợp bằng dụng cụ đo vòng van. Đặt vòng van nhân tạo vào vị trí. Khâu cố định vòng van nhân tạo vào vòng van bằng chỉ mũi chữ $U$ rời, có thể đệm thêm pledget vào các mũi chỉ nếu vòng van mỏng, yếu. Thử độ kín của van bằng bơm nước. 
Xử lý các thương tổn phối hợp nếu có: lấy huyết khối, khâu chân tiểu nhĩ trái, sửa van ba lá. Đuổi khí, đóng lại các buồng tim. Thả cặp động mạch chủ cho tim đập trở lại. Nếu có rung thất thì khử rung bằng dụng cụ chống rung. Nếu nhịp tim chậm thì hỗ trợ bằng máy tạo nhịp. Chạy máy hỗ trợ, ngừng máy, rút các cannula, trung hòa Heparin. Khâu phục hồi động mạch, tĩnh mạch đùi. Kiểm tra các đường khẩu. Câm máu. Đặt các điện cực và ống dẫn lưu. Đóng vết mổ ngực và đùi phải.

2.4. Xử lí số liệu: Số liệu thống kê được xử lý bằng phần mềm SPSS. Các biến số liên tục được mô tả bằng số trung bình \pm độ lệch chuẩn. Các biến số liên tục không tuân theo phân phối chuẩn được mô tả bằng số trung vị và khoảng tứ phân vị. Các biến số phân loại được mô tả bằng tần suất và tỉ lệ phần trăm.

\section{KẾT QUẢ NGHIÊN CỨU}

Từ tháng 1/2018 đến tháng 12/2020, có 45 bênh nhân được phẫu thuật sửa van hai lá qua đường mở ngực nhỏ bên phải có nội soi lồng ngực hỗ trợ.

Tuổi từ 20 đến 69 tuổi, trung bình là 49 $\pm 12,5$. Phần lớn bệnh nhân lứa tuổi trung niên và tuổi già. Tỷ lệ nam nữ xấp xỉ $1 / 1$.

3.1. Đăcc điểm trước mổ. Phần lớn bệnh nhân trước mổ có tình trạng chung ổn định, chỉ có một vài bệnh nhân cân nặng quá thấp, hoặc quá thừa cân. BMI trung bình là $21,3 \pm 1,6$. Tất cả các bệnh nhân đều có NYHA trước mổ từ II (73,3\%) đến III $(26,7 \%)$, không có bệnh nhân nào NYHA IV.

Các đặc điểm lâm sàng như NYHA, bệnh lý kèm theo, và các đặc điểm cận lâm sàng được mô tả trong bảng 3.1 dưới đây.

\begin{tabular}{|c|c|}
\hline Đặc điểm & Giá trị \\
\hline Tuối (giá trị trung bình \pm SD ) & $49 \pm 12,5$ \\
\hline \multicolumn{2}{|c|}{ Tiên sử và bệnh lý kèm theo } \\
\hline Tăng huyết áp & $16(35,6 \%)$ \\
\hline Đái tháo đường & $2(4,4 \%)$ \\
\hline Rung nhĩ & $3(6,7 \%)$ \\
\hline Thấp khớp cấp đã điều trị & $2(4,4 \%)$ \\
\hline hh động mạc & $1(2,2 \%)$ \\
\hline Suy thận & 0 \\
\hline \multicolumn{2}{|c|}{ Phân loại NYHA trước mố } \\
\hline & $33(73,3 \%)$ \\
\hline NYHA III & $12(26,7 \%)$ \\
\hline \multicolumn{2}{|c|}{ Các chỉ số trên siêu âm tim } \\
\hline Kích thước nhĩ trái (LA) (mm) & $43,7 \pm 5,6$ \\
\hline $\begin{array}{l}\text { Đường kích thất trái tâm trương } \\
\text { (Dd) (mm) }\end{array}$ & 57,0 \\
\hline
\end{tabular}

\begin{tabular}{|c|c|}
\hline $\begin{array}{l}\text { Đường kính thất trái tâm thu (Ds) } \\
(\mathrm{mm})\end{array}$ & $33,9 \pm 4,6$ \\
\hline $\begin{array}{l}\text { Phân suất tống máu thất trái } \\
\text { (LVEF) }(\%)\end{array}$ & $68,9 \pm 7,1$ \\
\hline $\begin{array}{l}\text { Ap lực động mạch phối tâm thu } \\
(\mathrm{mmHg})\end{array}$ & 13,9 \\
\hline $\begin{array}{l}\text { Chênh áp qua van hai lá tâm thu } \\
(\mathrm{mmHg})\end{array}$ & $9,0 \pm 3,0$ \\
\hline \multicolumn{2}{|c|}{ Độ hở van hai lá trên siêu âm tim } \\
\hline Không hở hoặc hở độ $1 / 4$ & 0 \\
\hline Độ 2/4 & 0 \\
\hline Độ 3/4 & $38(84,4 \%)$ \\
\hline Độ 4/4 & $7(15,6 \%)$ \\
\hline Hở van ba lá (từ độ $2 / 4$ & $6(13,3 \%)$ \\
\hline
\end{tabular}

3.2. Đặc điếm trong mố Bảng 3.2. Đặc điểm trong mổ

\begin{tabular}{|c|c|}
\hline & \\
\hline Đặc điếm & Giá trị \\
\hline Thời gian kẹp ĐMC (phút) & $93 \pm 19$ \\
\hline Thời gian chạy máy THNCT (phút) & $164 \pm 34$ \\
\hline Thời gian mố (phút) & $222 \pm 27$ \\
\hline Phân loại BN hở VHL theo C & arpentier \\
\hline Loai I & 0 \\
\hline Loại II & $43(95,6 \%)$ \\
\hline Loại IIIA & $2(4,4 \%)$ \\
\hline Loại IIIB & 0 \\
\hline Vị trí tốn thương & \\
\hline Lá trước đơn thuần & $4(8,9 \%)$ \\
\hline Lá sau đơn thuần & $34(75,5 \%)$ \\
\hline Cả 2 lá & $7(15,6 \%)$ \\
\hline Vị trí tốn thương theo Car & pentier \\
\hline $\mathrm{A} 1$ & $4(8,9 \%)$ \\
\hline $\mathrm{A} 2$ & $6(13,3 \%)$ \\
\hline A3 & $5(11,1 \%)$ \\
\hline P1 & $9(20 \%)$ \\
\hline P2 & $35(77,8 \%)$ \\
\hline P3 & $19(42,2 \%)$ \\
\hline
\end{tabular}

Kỹ thuật xử lý tốn thương van hai lá

\begin{tabular}{|c|c|}
\hline \multicolumn{2}{|c|}{ Ky thuật xứ lý tốn thương van haí la } \\
\hline Cắt tam giác & $4(8,9 \%)$ \\
\hline Cắt tứ giác & $17(37,8 \%)$ \\
\hline Butterfly & $1(2,2 \%)$ \\
\hline Khâu gấp nếp & $11(24,4 \%)$ \\
\hline DCNT & $9(20 \%)$ \\
\hline Edge-to-Edge & $6(13,3 \%)$ \\
\hline Đặt vòng van & $45(100 \%)$ \\
\hline Kích cõ̃ vòng van hai lá trung bình & $30,4 \pm 1,3$ \\
\hline
\end{tabular}

\subsection{Kết quả sau mố}

Bảng 3.3. Kết quả sau mổ

\begin{tabular}{|c|c|}
\hline Đặc điếm & Giá trị \\
\hline Thời gian thơ máy (giờ) & $18,9 \pm 7,5$ \\
\hline Thời gian nằm hồi sức (ngày) & $2,5 \pm 0,7$ \\
\hline Thời gian nằm viện (ngày) & $10,7 \pm 3,5$ \\
\hline Đánh giá sớm sau mổ cho thấy không có \\
bệnh nhẩn nào tử vong sớm sau mổ trong \\
nghiên cứu của chúng tôi. Có 2 trường hợp chảy
\end{tabular}


máu mổ lại (1 trường hợp máu chảy từ đường khâu nhĩ, 1 trường hợp máu cục màng phổi có điểm chảy từ lỗ chân dẫn lưu) đồng thời cũng ghi nhận 1 trường hợp nhiễm trùng nhẹ vết mổ đùi cân làm sạch và dùng kháng sinh điều trị, 1 trường hợp tràn dịch màng phổi cần đặt dẫn lưu, 2 trường hợp viêm phổi cần điều trị kháng sinh và không có nhiễm khuẩn huyết.

Kết quả siêu âm tim sau mổ ghi nhận 43 trường hợp không còn dòng hở qua van hai lá hoặc hở hai lá nhẹ ( $\leq 1 / 4)$; có 2 trường hợp còn hở vừa (độ 2/4) có triệu chứng lâm sàng ổn định được tiếp tục theo dõi.

Bảng 3.4. Thay đổi về siêu âm tim lúc trước mổ so với lúc ra viện:

\begin{tabular}{|c|c|c|c|c|}
\hline \multicolumn{2}{|c|}{$\begin{array}{c}\text { Các chỉ số SÂ } \\
\text { tim }\end{array}$} & $\begin{array}{c}\text { SẦ trước } \\
\text { mổ } \\
\text { TB } \pm \text { độ } \\
\text { lêch }\end{array}$ & $\begin{array}{c}\text { SÂ lúc ra } \\
\text { viện } \\
\text { TB } \pm \text { độ } \\
\text { lêch }\end{array}$ & $\mathbf{p}$ \\
\hline \multicolumn{2}{|c|}{$\mathrm{NT}(\mathrm{mm})$} & $43,7 \pm 5,6$ & $38,0 \pm 6,1$ & $<0,001$ \\
\hline \multicolumn{2}{|c|}{$\mathrm{Dd}(\mathrm{mm})$} & $57,0 \pm 4,9$ & $46,6 \pm 4,0$ & $<0,001$ \\
\hline \multicolumn{2}{|c|}{$\mathrm{Ds}(\mathrm{mm})$} & $33,9 \pm 4,6$ & $31,1 \pm 4,9$ & $<0,001$ \\
\hline \multicolumn{2}{|c|}{ ĐKTP (mm) } & $20,0 \pm 3,0$ & $22,0 \pm 6,6$ & 0,056 \\
\hline \multicolumn{2}{|c|}{ EF (\%) } & $68,9 \pm 7,1$ & $63,3 \pm 8,0$ & $<0,001$ \\
\hline \multicolumn{2}{|c|}{ ALĐMPTT } & $38,1 \pm 13,9$ & $28,0 \pm 5,6$ & $<0,001$ \\
\hline $\begin{array}{c}\text { Chênh áp } \\
\text { qua van } \\
\text { hai lá }\end{array}$ & $\begin{array}{l}\text { Tâm } \\
\text { thu }\end{array}$ & $9,0 \pm 3,0$ & $5 \pm 2,3$ & 0.027 \\
\hline
\end{tabular}

3.4. Kết quả trung hạn. Thời gian theo dõi của trung bình của chúng tôi là 16,4 $\pm 5,2$ tháng. Thời gian theo dõi dài nhất là 40,5 tháng.

Có 41 trường hợp $(91,1 \%)$ kiểm tra siêu âm tim trung hạn không hở hoặc hở hai lá nhẹ. Có 3 bệnh nhân $(6,7 \%)$ hở van hai lá vừa (độ $2 / 4)$. Có 1 bệnh nhân có kết quả siêu âm sau mổ 6 tháng hở van hai lá nặng và đã được thay van hai lá sau đó. Đây là trường hợp sửa van hai lá tổn thương đứt nhiều dây chằng lá sau được phẫu thuật sửa van hai lá do đứt nhiều dầy chằng ở P2P3 được phẫu thuật cắt tứ giác lá sau, đặt vòng van số 30 . Trong quá trình test van bằng nước và siêu âm tim thực quản trong mổ có dòng hở nhẹ. Siêu âm qua thành ngực kiểm tra sau mổ và lúc ra viện của $B N$ có hở hai lá vừa (2/4). BN được theo dõi khám định kỳ, siêu âm tim kiểm tra lại sau 1 và 6 tháng dòng hở tăng lên và được thay van hai lá sau đó.

Hiện tất cả bệnh nhân được theo dõi của chúng tôi đến hiện tại không có nào bệnh nhân tử vong. Song có 1 bệnh nhân xuất hiện tai biến mạch máu não sau mổ 1 năm đã được điều trị nội khoa ổn định, di chứng yếu nửa người.

Bảng 3.5. Thay đổi trên siêu âm tim trung hạn so với trước mổ

\begin{tabular}{|c|c|c|c|}
\hline $\begin{array}{c}\text { Các chỉ số } \\
\text { SÂ tim }\end{array}$ & $\begin{array}{c}\text { SÁ trước } \\
\text { mổ } \\
\text { TB } \pm \text { độ } \\
\text { lêch }\end{array}$ & 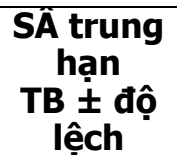 & $\mathbf{p}$ \\
\hline $\mathrm{NT}(\mathrm{mm})$ & $43,7 \pm 5,6$ & $37,3 \pm 6,8$ & $<0,001$ \\
\hline $\mathrm{Dd}(\mathrm{mm})$ & $57,0 \pm 4,9$ & $45,3 \pm 5,2$ & $<0,001$ \\
\hline $\mathrm{Ds}(\mathrm{mm})$ & $33,9 \pm 4,6$ & $30,2 \pm 4,3$ & $<0,001$ \\
\hline ĐKTP (mm) & $20,0 \pm 3,0$ & $21,2 \pm 4,7$ & \begin{tabular}{|l|}
0.063 \\
\end{tabular} \\
\hline EF (\%) & $68,9 \pm 7,1$ & 65, & 0,026 \\
\hline ALĐMPTT & $38,1 \pm 13,9$ & $26,7 \pm 5,2$ & $<0,001$ \\
\hline \begin{tabular}{c|c}
$\begin{array}{c}\text { Chênh áp } \\
\text { qua van } \\
\text { hai lá }\end{array}$ & $\begin{array}{c}\text { Tâm } \\
\text { thu }\end{array}$ \\
\end{tabular} & $0 \pm 3,0$ & 3,1 & 043 \\
\hline
\end{tabular}

\section{BÀN LUÂ̂N}

Phẫu thuật sửa van hai lá ít xâm lấn đã được chứng minh là làm giảm các biến chứng sau phẩu thuật, giúp hồi phục nhanh, thời gian nằm viện ngắn hơn, ít đau hơn, hình thức thẩm mỹ tốt hởn. Năm 2010, tuyê̂n bố đồng thuận của hiệp hội quốc tế về phẫu thuật lồng ngực ít xâm lẩn (ISMICS) nhấn mạnh rằng phẩu thuật van hai lá ít xâm lấn có thể là một giải pháp thay thế cho phẫu thuật van hai lá thông thường, do có tỷ lệ tử vong ngắn hạn và dài hạn không khác biệt so với mổ mở truyền thống, tỷ lệ biến chứng được cải thiện (biến chứng thận, phổi, tim, và mức độ đau sau mổ), giảm các biến chứng trên xương ức, truyền máu, rung nhĩ sau mổ, thời gian thở máy và hồi sức cũng như thời gian nằm viện.

Nghiên cứu đánh giá kết quả sớm và trung hạn của bệnh nhân được phẫu thuật sửa van hai lá ít xâm iấn qua đường mở nhỏ ngực phải tại bệnh viện của chúng tôi. Dựa vào những phân tích hiện tại có thể thấy quy trình phẫu thuật cửa chúng tôi là an toàn nhờ vào kết quả hậu phẫu sớm tốt, độ hở hai lá sau mổ ở mức thấp. Không có trường hợp nào phải chuyển mở xương ức hay mở rộng đường mở ngực. Theo dõi 30 ngày sau phẫu thuật tỉ lệ tử vong là $0 \%$; có 2 trường hợp chảy máu mổ lại (1 trường hợp máu chảy từ đường khâu nhĩ, 1 trường hợp máu cục màng phổi có điểm chảy từ lô̂ chân dẩn lưu).

Kết quả trung hạn của chúng tôi cũng tương đối khả quan, chỉ có 1 bệnh nhân cần phẩu thuật thay van hai lá do dòng hở qua van hai lá tăng lên, còn lại 44 bệnh nhân có kết quả siêu âm tim cũng như triệu chứng lâm sàng cải thiện ổn định. Tất cả bệnh nhân được theo dõi của chúng tôi đến hiện tại không có nào bệnh nhân tử vong. Có 1 bệnh nhân xuất hiện tai biến mạch máu não sau mổ 1 năm đã được điều trị nội khoa ổn định, di chứng yếu nửa người.

Thời gian tuần hoàn ngoài cơ thể và thời gian kẹp động mạch chủ trong phẫu thuật van hai lá 
ít xâm lấn dài hơn có ý nghĩa thống kê so với phẫu thuật kinh điển, đặc biệt đối với sửa van hai lá. Vì vậy, trong giai đoạn đâu chúng tôi chọn những bệnh nhân có tổn thương van hai lá đơn giản, thường là sa lá sau phần $\mathrm{P} 2$, chức năng thất trái tốt, không hoặc tăng nhẹ áp lực động mạch phổi. Về sau khi đã vượt qua đường cong huấn luyện, chúng tôi có thể mở rộng chỉ định cũng như phương pháp mổ. Tuy nhiên, với những trường hợp tổn thương van phức tạp mà vẫn còn khả năng sửa, chúng tôi ưu tiên dùng phương pháp mổ mở để sửa van.

Phẫu thuật sửa van hai lá 1 trong những phẫu thuật đòi hỏi nhiều kĩ năng nhất trong các phẫu thuật tim có thể thực hiên được bằng phương pháp ít xâm lấn. So với thay van hai lá, phẫu thuật sửa van hai lá đem lại nhiều lợi ích vượt trội cho người bệnh: Cải thiện chức năng thất trái, giảm tî lệ tử vong sớm và dài hạn, giảm các biến chứng do việc sử dụng thuốc kháng đông loại kháng Vitamin $\mathrm{K}$ lâu dài, giảm tỉ lệ phẫu thuật lại. Chúng tôi tin rằng cùng với sự phát triển của khoa học kĩ thuật, đặc biệt ứng dụng của các hệ thống robot đã triển khai ở các nước phát triển, chất lượng của phẫu thuật nội soi sửa van hai lá sẽ ngày càng được cải thiện và nâng cao.

\section{KẾT LUẬN}

Phẫu thuật sửa van hai lá ít xâm lấn bằng đường mở ngực nhỏ có nội soi lồng ngực hỗ trợ khả thi, an toàn và có kết quả sớm cũng như trung hạn khả quan tại bệnh viện của chúng tôi. Tuy nhiên vẫn còn những thách thức kĩ thuật và đòi hỏi đường cong huấn luyện dài cho nên cần có sự đầu tư nhân lực cũng như trang thiết bị. Việc chọn lựa bệnh nhân hợp lý và tuân thủ các quy định về an toàn phẫu thuật sẽ giúp đem lại kết quả tốt và đảm bảo sự an toàn cho người bệnh.

\section{TÀI LIỆ THAM KHẢO}

1. Carpentier A.F., Adams D.H., Filsoufi F. và cộng sứ. (2010), Carpentier's reconstructive valve surgery: from valve analysis to valve reconstruction, Saunders Elsevier, Maryland Heights, Mo.

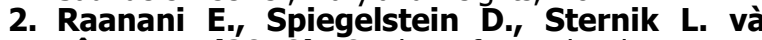
cộng sự. (2010). Quality of mitral valve repair: Median sternotomy versus port-access approach. The Journal of Thoracic and Cardiovascular Surgery, 140(1), 86-90.

3. Cao C., Gupta S., Chandrakumar D. và cộng sứ. (2013). A meta-analysis of minimally invasive versus conventional mitral valve repair for patients with degenerative mitral disease. Annals of cardiothoracic surgery, 2(6), 11.

4. McClure R.S., Cohn L.H., Wiegerinck E. và cộng sự. (2009). Early and late outcomes in minimally invasive mitral valve repair: An elevenyear experience in 707 patients. The Journal of Thoracic and Cardiovascular Surgery, 137(1), 70-75.

5. Davierwala P.M., Seeburger J., Pfannmueller B. và cộng sự. (2013). Minimally invasive mitral valve surgery: "The Leipzig experience". Annals of cardiothoracic surgery, 2(6), 7.

6. Sündermann S.H., Sromicki J., Rodriguez Cetina Biefer H. và công sứ. (2014). Mitral valve surgery: Right lateral minithoracotomy or sternotomy? A systematic review and metaanalysis. The Journal of Thoracic and Cardiovascular Surgery, 148(5), 1989-1995.e4.

7. Falk V., Cheng D.C.H., và Martin J. (2011) Minimally Invasive versus Open Mitral Valve Surgery a Consensus Statement of the International Society of Minimally Invasive Coronary Surgery (ISMICS) 2010. 6(2), 11.

\section{VAI TRÒ CỦA KHOẢNG THỜI GIAN TPEAK - TEND TRONG PHÂN TẦ NGUY CƠ Ở BÊ̂NH NHÂN CÓ ĐIỆN TÂM ĐỒ DANG BRUGADA}

\section{TÓM TẮT}

Mục tiêu: (1) Khảo sát khoảng thời gian TpeakTend và tỉ lệ Tpeak-Tend/QT ở bệnh nhân có điện tâm

\footnotetext{
${ }^{1}$ Trường Đai Hoc Y Hà Nôi

2 Viện Tim mạch Việt Nam - Bệnh viện Bạch Mai

${ }^{3}$ Trường Đại Học Y Dược-Đại học Quốc Gia Hà Nội.

Chịu trách nhiếm chính: Phạm Trần Linh

Email: ptlinhmd@gmail.com

Ngày nhận bài: 29.7.2021

Ngày phản biên khoa họ: 30.9.2021

Ngày duyệt bài: 5.10 .2021
}

\section{Phạm Trung Hiếu 1,2, Phạm Trần Linh ${ }^{2,3}$, Viên Hoàng Long,3, Lê Thị Lan Hương1.}

đồ dạng Brugada. (2)Đánh giá giá trị của khoảng thời gian Tpeak- Tend và tî lê Tpeak- Tend / QT trong phân tâng nguy cơ rối loạn nhịp thất ở những bệnh nhân trên. Phương pháp nghiên cứu: Nghiên cứu mô tả cắt ngang 41 bệnh nhân có điện tâm đồ dạng Brugada được tiến hành thăm dò điện sinh lý tại Viên Tim Mạch - Bệnh viện Bạch Mai. So sánh khoảng thời gian TpTe và tỉ lệ TpTe/QT với kết quả thăm dò điện sinh lý, tìm mối liên quan. Kết quả: 41 bệnh nhân có điên tâm đồ dang Brugada tham gia nghiên cứu có độ tuổi trung bình là $49 \pm 11$ tuổi, nam giới chiếm 95,1\%. Có 24 bệnh nhân (chiếm $58.55 \%$ ) thăm dò điên sinh lý dương tính gây nhịp nhanh thất đa hình thái, rung thất. Khoảng thời gian Tpeak-Tend dài hơn đáng kể ở 